\title{
Highly Efficient Method for Synthesis of N-Amino-2-Pyridone Derivatives in the Presence of Catalysts such as Magnesium Oxide (MgO) and Bismuth(III) Nitrate Pentahydrate $\left(\mathrm{Bi}\left(\mathrm{NO}_{3}\right)_{3} \cdot 5 \mathrm{H}_{2} \mathrm{O}\right)$
}

\author{
Mohammad Seifi, Mahboobeh Khajehasani Rabori, Hassan Sheibani* \\ Department of Chemistry, Shahid Bahonar University of Kerman, Kerman, Iran \\ Email: "'hsheibani@mail.uk.ac.ir
}

Received January 31, 2013; revised March 28, 2013; accepted May 1, 2013

Copyright (C) 2013 Mohammad Seifi et al. This is an open access article distributed under the Creative Commons Attribution License, which permits unrestricted use, distribution, and reproduction in any medium, provided the original work is properly cited.

\begin{abstract}
Magnesium oxide $(\mathrm{MgO})$ and bismuth(III) nitrate pentahydrate as highly effective catalysts which have catalyzed the three-component reaction of cyanoacetic acid hydrazide, aldehydes and malononitrile to prepare of the corresponding $\mathrm{N}$-amino-2-pyridones. These catalysts are inexpensive and easily obtained, stable and storable, easily recycled and reused for several cycles with consistent activity.
\end{abstract}

Keywords: Magnesium Oxide (MgO); Bismuth(III) Nitrate Pentahydrate; Cyanoacetic Acid Hydrazide; N-Amino-2-Pyridone

\section{Introduction}

The development of heterocyclic compounds such as pyridones is a topic of current interest because of their presence in numerous natural products along with the wide spectrum of physiological activities displayed by this class of compounds [1-3]. It is well known that the 2-pyridone derivatives are valuable building blocks in natural products synthesis and also a versatile synthon for the synthesis of a variety of other nitrogen-containing heterocyclic compounds, such as $\beta$-lactams, quinolizidines, pyridines, piperidines, and indolizidine alkaloids [4]. The diene portion of these molecules can undergo Diels-Alder cycloaddition reactions with dienophiles, or one double bond may act as a dienophile to an added diene [5]. So they have been applied as a key synthetic intermediate to synthesize some complex natural products [6]. A large number of methods have been developed for the synthesis of 2-pyridones and their derivatives [7]. The most common strategies involve the construction of the heterocyclic compounds from easily available starting materials. Due to the importance of 2-pyridone skeleton, to develop new and efficient methodologies for diversely functionalized construction of 2-pyridone is still highly desired. The development of efficient and environmen-

${ }^{*}$ Corresponding author. tally acceptable synthetic methods is an important task of modern chemistry. Conventional organic syntheses are generally based on homogeneous or heterogeneous catalysts. Magnesium oxide (MgO) and bismuth(III) nitrate pentahydrate are known as heterogeneous catalysts and commercially available reagents and require no special handling. Magnesium oxide ( $\mathrm{MgO})$, obtained using a novel but simple procedure, was systematically investigated as a heterogeneous base catalyst for reactions taking place in the liquid phase, specifically the Michael addition and the Knoevenagel condensation [8]. Bismuth (III) nitrate pentahydrate can act as an effective Lewis acid, and it can be used successfully in the presence of commercially available solvents without any drying or treatment. The use of bismuth nitrate derivatives as catalysts in organic synthesis has increased considerably over the years. A literature survey revealed that bismuth (III) nitrate pentahydrate has been used for conversion of thiocarbonyls to their carbonyl compounds [9], aromatic nitration [10], protection of carbonyl compound [11], Michael reactions [12], synthesis of coumarins [13] and etc. In continuing our interest in the synthesis of heterocyclic compounds in the presence of base or acid catalysts [14-16], we now wish to describe the synthesis of $\mathrm{N}$-amino-2-pyridones in the presence of magnesium oxide $(\mathrm{MgO})$ as a highly effective heterogeneous base catalyst, 
and by using bismuth(III) nitrate pentahydrate as an effective Lewis acid catalyst.

\section{Experimental}

\subsection{General Information}

Malononitrile, aldehydes, $\mathrm{Mg}(\mathrm{OH})_{2}, \mathrm{MgO}$ and bismuth(III) nitrate pentahydrate were commercially available, and were obtained from Merck Chemical Co. and used without further purification. Cyanoacetic acid hydrazide was prepared according to a literature procedure [17]. Melting points were measured on an Electrothermal-9100 apparatus and are uncorrected. IR spectra were recorded on a Brucker FT-IR Tensor 27 infrared spectrophotometer. The proton NMR spectra were recorded with a BRUKER DRX-300 AVANCE spectrometer.

\subsection{Catalyst Preparation}

High surface area $\mathrm{MgO}$ used in this study were obtained by rehydrated $\mathrm{Mg}(\mathrm{OH})_{2}$ at $450^{\circ} \mathrm{C}$ for $2 \mathrm{~h}$. A calcination temperature of $400^{\circ} \mathrm{C}-500^{\circ} \mathrm{C}$ gave maximum conversion. When the catalyst was calcined above $500{ }^{\circ} \mathrm{C}$, the activity of $\mathrm{MgO}$ decreased and continued to decrease as the calcination temperature increased. The maximum surface area was obtained after calcining the samples at $400^{\circ} \mathrm{C}$ $500^{\circ} \mathrm{C}[8]$.

\subsection{General Procedure for the Preparation of N-Amino-2-pyridone Derivatives}

A mixture of cyanoacetic acid hydrazide 1 (2 mmol), aldehyde 2 (2 mmol), malononitrile 3 (2 $\mathrm{mmol})$, and commercial $\mathrm{MgO}$ (0.25 g), high surface area $\mathrm{MgO}(0.25$ g) or $\mathrm{Bi}\left(\mathrm{NO}_{3}\right)_{3} \cdot 5 \mathrm{H}_{2} \mathrm{O}(0.04 \mathrm{~g})$ in ethanol $(10 \mathrm{~mL})$ was refluxed with stirring for the time reported in Table 4 (the progress of the reaction being monitored by TLC and was used hexane/ethyl acetate as an eluent). When the reaction was completed as indicated by TLC, the crude product 4 was precipitated from the reaction mixture by cooling, and the solid was filtered and recrystallized with ethanol to get pure product.

\subsection{1,6-Diamino-2-oxo-4-phenyl-1,2- dihydropyridine-3,5-dicarbonitrile (4a)}

Withe crystals; mp. $237^{\circ} \mathrm{C}-238^{\circ} \mathrm{C}$.IR $\left(\mathrm{KBr}, v \max / \mathrm{cm}^{-1}\right)$ : 3440, $3394\left(2 \mathrm{NH}_{2}\right), 2220,2216(2 \mathrm{CN}), 1640(\mathrm{C}=\mathrm{O})$, $1560(\mathrm{C}=\mathrm{C}) .{ }^{1} \mathrm{H}$ NMR (300 MHz, DMSO-d 6 ): 8.85 (broad, s, 2H, $\mathrm{NH}_{2}$ ), 7.95 - 6.92 (m, 5H, Ar), 5.23 (broad, $\mathrm{s}, 2 \mathrm{H}, \mathrm{NH}_{2}$ ).

\subsection{1,6-Diamino-4-(4-chlorophenyl)-2-oxo-1,2- dihydropyridine-3,5-dicarbonitrile (4f)}

Withe crystals; mp. $243^{\circ} \mathrm{C}-245^{\circ} \mathrm{C}$.IR $\left(\mathrm{KBr}, v_{\max } / \mathrm{cm}^{-1}\right)$ :
3467, $3382\left(2 \mathrm{NH}_{2}\right), 2220,2216(2 \mathrm{CN}), 1645(\mathrm{C}=\mathrm{O})$, $1562(\mathrm{C}=\mathrm{C}) .{ }^{1} \mathrm{H}$ NMR (300 MHz, DMSO-d 6 ): 8.28 (broad, s, 2H, $\mathrm{NH}_{2}$ ), 7.84 - 7.01 (m, 4H, Ar), 5.24 (broad, $\mathrm{s}, 2 \mathrm{H}, \mathrm{NH}_{2}$ ).

\section{Results and Discussion}

In the present protocol as exhibited in Scheme 1 the three-component reaction of cyanoacetic acid hydrazide $\mathbf{1}$ arylaldehydes $\mathbf{2 a}-\mathbf{h}$ and malononitrile $\mathbf{3}$ have been investigated in the presence of catalysts such as magnesium oxide ( $\mathrm{MgO})$ as a base catalyst and also bismuth(III) nitrate pentahydrate as an effective Lewis acid catalyst. The N-amino-2-pyridone derivatives $\mathbf{4 a - h}$ were produced under conventional conditions and in a short experimenttal time.

In recent years, there has been increasing emphasis on the design and use of environmentally friendly solid acid and base catalysts to reduce the amount of toxic waste and by products arising from chemical processes prompted by stringent environment protection laws [18].

Several solid base and acid catalysts have been reported as being effective in the reactions that involve the Michael addition and the Knoevenagel condensation. Magnesium oxide (MgO) and bismuth(III) nitrate pentahydrate were systematically investigated as heterogeneous base and acid catalysts for reactions taking place in the liquid phase, specifically Michael addition and Knoevenagel condensation [9,10]. Since the three-component reaction of cyanoacetic acid hydrazide $\mathbf{1}$ arylaldehydes $\mathbf{2 a - h}$ and malononitrile $\mathbf{3}$ involve both Knoevenagel condensation and Michael addition, we have studied the effect of catalytic activity two types of magnesium oxides such as commercial $\mathrm{MgO}(\mathrm{CM}-\mathrm{MgO})$ and high surface area $\mathrm{MgO}$ (HSA-MgO) and also bismuth(III) nitrate pentahydrate as an effective Lewis acid catalyst on these reactions. In order to optimize the reaction conditions, we used some polar and non polar solvents in the three-component reaction of cyanoacetic acid hydrazide, benzaldehyde and malononitrile in the presence of catalysts such as commercial $\mathrm{MgO}$, high surface area $\mathrm{MgO}$ and bismuth (III) nitrate pentahydrate as model reactions to investigate the effects of solvent for preparing com-

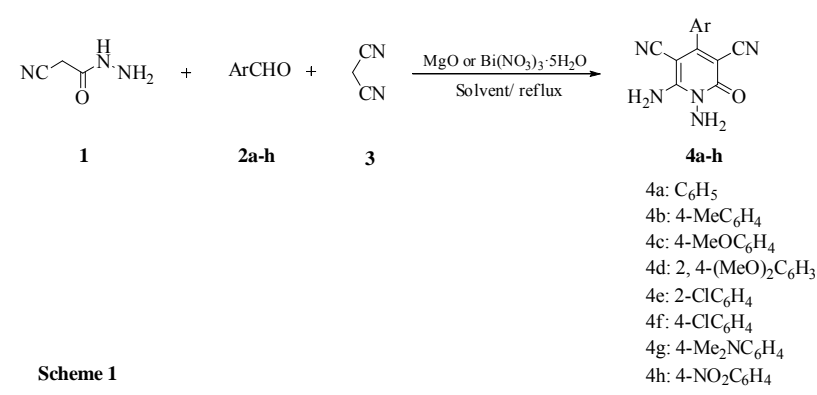

Scheme 1. Synthesis of $\mathrm{N}$-amino-2-pyridone derivatives. 
pound 4a. In each case, the substrates were mixed together with $312 \mathrm{~mol} \%$ magnesium oxides or $5 \mathrm{~mol} \%$ $\mathrm{Bi}\left(\mathrm{NO}_{3}\right)_{3} \cdot 5 \mathrm{H}_{2} \mathrm{O}$ agitated with $10 \mathrm{~mL}$ solvent under conventional heating. The results are shown in Table 1. It is noteworthy to mention that the polar solvents such as ethanol afford better yields than non polar solvents. So these reactions were mostly unsuccessful in toluene.

We also optimized the quantity of catalysts. The best results were obtained when the reactions were carried out in the presence of $312 \mathrm{~mol} \%$ commercial $\mathrm{MgO}, 312$ $\mathrm{mol} \%$ high surface area $\mathrm{MgO}$ and $5 \mathrm{~mol} \% \mathrm{Bi}\left(\mathrm{NO}_{3}\right)_{3} \cdot 5 \mathrm{H}_{2} \mathrm{O}$. The results are shown in Table 2 .

Table 1. Solvent effects on the three-component reaction for the synthesis of 4 a.

\begin{tabular}{ccccc}
\hline Entry & Solvent & Catalyst & Time (min) & Yield (\%) \\
\hline 1 & Acetonitrile & ${ }^{\mathrm{a}} \mathrm{CM}-\mathrm{MgO}$ & 100 & 80 \\
2 & Acetonitrile & ${ }^{\mathrm{b}} \mathrm{HSA}-\mathrm{MgO}$ & 60 & 90 \\
3 & Acetonitrile & $\mathrm{Bi}\left(\mathrm{NO}_{3}\right)_{3} \cdot 5 \mathrm{H}_{2} \mathrm{O}$ & 80 & 83 \\
4 & Methanol & ${ }^{\mathrm{a}} \mathrm{CM}^{-\mathrm{MgO}}$ & 35 & 87 \\
5 & Methanol & ${ }^{\mathrm{b}} \mathrm{HSA}-\mathrm{MgO}$ & 7 & 92 \\
6 & Methanol & $\mathrm{Bi}\left(\mathrm{NO}_{3}\right)_{3} \cdot 5 \mathrm{H}_{2} \mathrm{O}$ & 12 & 89 \\
7 & Ethanol & ${ }^{\mathrm{a}} \mathrm{CM}^{-\mathrm{MgO}}$ & 30 & 89 \\
8 & Ethanol & ${ }^{\mathrm{b}} \mathrm{HSA}-\mathrm{MgO}$ & 5 & 95 \\
9 & Ethanol & $\mathrm{Bi}\left(\mathrm{NO}_{3}\right)_{3} \cdot 5 \mathrm{H}_{2} \mathrm{O}$ & 8 & 91 \\
\hline
\end{tabular}

${ }^{\mathrm{a} C o m m e r c i a l ~} \mathrm{MgO}{ }^{\mathrm{b}} \mathrm{High}$ surface area $\mathrm{MgO}$.

Table 2. Optimized the quantity of catalysts on the threecomponent reaction for the synthesis of $4 a$.

\begin{tabular}{|c|c|c|c|c|}
\hline Entry & Catalyst & Mol\% catalyst & Time (min) & $\begin{array}{c}\text { Yield } \\
(\%)\end{array}$ \\
\hline 1 & CM-MgO & 250 & 35 & 85 \\
\hline 2 & HSA-MgO & 250 & 10 & 88 \\
\hline 3 & $\mathrm{Bi}\left(\mathrm{NO}_{3}\right)_{3} \cdot 5 \mathrm{H}_{2} \mathrm{O}$ & 5 & 8 & 91 \\
\hline 4 & CM-MgO & 312 & 30 & 87 \\
\hline 5 & HSA-MgO & 312 & 5 & 95 \\
\hline 6 & $\mathrm{Bi}\left(\mathrm{NO}_{3}\right)_{3} \cdot 5 \mathrm{H}_{2} \mathrm{O}$ & 10 & 10 & 90 \\
\hline 7 & CM-MgO & 375 & 32 & 87 \\
\hline 8 & HSA-MgO & 375 & 8 & 90 \\
\hline 9 & $\mathrm{Bi}\left(\mathrm{NO}_{3}\right)_{3} \cdot 5 \mathrm{H}_{2} \mathrm{O}$ & 15 & 10 & 88 \\
\hline
\end{tabular}

Also we attempted to reuse the catalysts by a variety of methods (Table 3). Direct reuse of the catalysts (Table 3 , entry $2,6,10$ ) led to a greater than $20 \%$ decrease in activity while washing of the catalysts with dichloromethane and ethyl acetate, prior to reuse also resulted in lower conversions (Table 3, entry 3, 4, 7, 8, 11, 12). This phenomenon probably arose because the reactant and product were not completely desorbed from commercial $\mathrm{MgO}$, high surface area $\mathrm{MgO}$ and $\mathrm{Bi}\left(\mathrm{NO}_{3}\right)_{3} \cdot 5 \mathrm{H}_{2} \mathrm{O}$ and therefore, the active sites were blocked.

In this investigation, the three-component reaction of cyanoacetic acid hydrazide $\mathbf{1}$ arylaldehydes $\mathbf{2 a - h}$ and malononitrile $\mathbf{3}$ were carried out in boiling ethanol in the presence of two kinds of magnesium oxide $(\mathrm{MgO})$ as base catalysts and bismuth(III) nitrate pentahydrate as an effective Lewis acid catalyst to produce the N-amino-2pyridone derivatives $\mathbf{4 a - h}$ in high yields. The results of these three-component reactions were summarized in Table 4. As shown in Table 4, the reaction yields are markedly affected by the catalyst, and optimum results were obtained when reactions were run in the presence of high surface area $\mathrm{MgO}$. Also these reactions were carried out in the presence of base catalysts such as piperidine or triethylamine in thermal conditions, which the products were obtained in low yields and a long reaction time [19].

Table 3. Reusability of magnesium oxides and $\mathrm{Bi}\left(\mathrm{NO}_{3}\right)_{3} \cdot 5 \mathrm{H}_{2} \mathrm{O}$ on the three-component reaction for the synthesis of $4 \mathrm{a}$.

\begin{tabular}{|c|c|c|c|}
\hline Entry & Catalyst & Time (min) & Yield (\%) \\
\hline 1 & $\mathrm{CM}-\mathrm{MgO}\left(1^{\text {st }}\right.$ use $)$ & 30 & 89 \\
\hline 2 & $\mathrm{CM}-\mathrm{MgO}^{\mathrm{a}}$ (2 $2^{\text {st }}$ use $)$ & 60 & 80 \\
\hline 3 & $\mathrm{CM}-\mathrm{MgO}^{\mathrm{b}}\left(2^{\text {st }}\right.$ use $)$ & 42 & 85 \\
\hline 4 & $\mathrm{CM}-\mathrm{MgO}^{\mathrm{c}}\left(2^{\mathrm{st}}\right.$ use $)$ & 45 & 83 \\
\hline 5 & HSA-MgO $\left(1^{\text {st }}\right.$ use $)$ & 5 & 95 \\
\hline 6 & HSA-MgO ${ }^{\mathrm{a}}\left(1^{\text {st }}\right.$ use $)$ & 20 & 82 \\
\hline 7 & HSA-MgO ${ }^{\mathrm{b}}\left(1^{\text {st }}\right.$ use $)$ & 12 & 88 \\
\hline 8 & HSA-MgO ${ }^{\mathrm{c}}\left(1^{\text {st }}\right.$ use $)$ & 15 & 86 \\
\hline 9 & $\mathrm{Bi}\left(\mathrm{NO}_{3}\right)_{3} \cdot 5 \mathrm{H}_{2} \mathrm{O}\left(1^{\mathrm{st}}\right.$ use $)$ & 8 & 91 \\
\hline 10 & $\mathrm{Bi}\left(\mathrm{NO}_{3}\right)_{3} .5 \mathrm{H}_{2} \mathrm{O}^{\mathrm{a}}\left(1^{\mathrm{st}}\right.$ use $)$ & 28 & 80 \\
\hline 11 & $\mathrm{Bi}\left(\mathrm{NO}_{3}\right)_{3} \cdot 5 \mathrm{H}_{2} \mathrm{O}^{\mathrm{b}}\left(1^{\mathrm{st}}\right.$ use $)$ & 20 & 85 \\
\hline 12 & $\mathrm{Bi}\left(\mathrm{NO}_{3}\right)_{3} .5 \mathrm{H}_{2} \mathrm{O}^{\mathrm{c}}\left(1^{\mathrm{st}}\right.$ use $)$ & 22 & 80 \\
\hline
\end{tabular}

${ }^{\mathrm{a}}$ Direct reuse of the catalysts. ${ }^{\mathrm{b}} \mathrm{Commercial} \mathrm{MgO}$, high surface area $\mathrm{MgO}$ and $\mathrm{Bi}\left(\mathrm{NO}_{3}\right)_{3} \cdot 5 \mathrm{H}_{2} \mathrm{O}$ were washed with dichloromethane. ${ }^{\mathrm{c}} \mathrm{Commercial} \mathrm{MgO}$, high surface area $\mathrm{MgO}$ and $\mathrm{Bi}\left(\mathrm{NO}_{3}\right)_{3} \cdot 5 \mathrm{H}_{2} \mathrm{O}$ were washed with ethylacetate. 
Table 4. Synthesis of compounds $4 a-h$ in the presence of base and acid catalysts.

\begin{tabular}{|c|c|c|c|c|c|c|c|}
\hline \multirow[b]{2}{*}{ Compd. No. } & \multirow[b]{2}{*}{$\mathrm{Ar}$} & \multicolumn{2}{|c|}{ Commercially available $\mathrm{MgO}$} & \multicolumn{2}{|c|}{$\mathrm{Bi}\left(\mathrm{NO}_{3}\right)_{3} \cdot 5 \mathrm{H}_{2} \mathrm{O}$} & \multirow[b]{2}{*}{$\begin{array}{c}\text { M. P. } \\
\text { observed }\left({ }^{\circ} \mathrm{C}\right)\end{array}$} & \multirow[b]{2}{*}{$\begin{array}{l}\text { M. P. } \\
\text { reported }\left({ }^{\circ} \mathrm{C}\right)\end{array}$} \\
\hline & & $\begin{array}{l}\text { Time } \\
(\mathrm{min})\end{array}$ & $\begin{array}{l}\text { Yield } \\
(\%)\end{array}$ & $\begin{array}{l}\text { Time } \\
(\mathrm{min})\end{array}$ & $\begin{array}{l}\text { Yield } \\
(\%)\end{array}$ & & \\
\hline $4 a$ & $\mathrm{C}_{6} \mathrm{H}_{5}$ & 30 & 89 & 5 & 95 & $237-238$ & 240 [19] \\
\hline $4 b$ & $4-\mathrm{MeC}_{6} \mathrm{H}_{4}$ & 35 & 85 & 8 & 92 & 238 & 240 [19] \\
\hline $4 \mathrm{c}$ & 4- $\mathrm{MeOC}_{6} \mathrm{H}_{4}$ & 40 & 82 & 10 & 90 & $222-224$ & $225[19]$ \\
\hline $4 d$ & 2,4-(MeO) $)_{2} \mathrm{C}_{6} \mathrm{H}_{3}$ & 45 & 80 & 12 & 88 & $251-253$ & 255 [19] \\
\hline $4 \mathrm{e}$ & $2-\mathrm{ClC}_{6} \mathrm{H}_{4}$ & 28 & 90 & 4 & 96 & 248 & $250[19]$ \\
\hline $4 \mathrm{f}$ & $4-\mathrm{ClC}_{6} \mathrm{H}_{4}$ & 25 & 92 & 3 & 98 & $242-243$ & 245 [19] \\
\hline $4 \mathrm{~g}$ & $4-(\mathrm{Me})_{2} \mathrm{~N} \mathrm{C}_{6} \mathrm{H}_{4}$ & 45 & 80 & 10 & 90 & $247-249$ & 250 [19] \\
\hline $4 \mathrm{~h}$ & $4-\mathrm{NO}_{2} \mathrm{C}_{6} \mathrm{H}_{4}$ & 27 & 90 & 4 & 96 & $226-228$ & 230 [19] \\
\hline
\end{tabular}

\section{Conclusion}

In summary, there are no doubt these effective catalysts which provide a new and useful method to synthesis $\mathrm{N}$-amino-2-pyridone derivatives in a three-component reaction of cyanoacetic acid hydrazide, aldehyde and malononitrile. These catalysts show environmental friendly character, which are inexpensive and easily obtained. Moreover, the procedure offers several advantages including high yields, operational simplicity, clean reaction conditions and minimum pollution of the environment, which makes it a useful and attractive process for the synthesis of these compounds.

\section{Acknowledgements}

The authors express appreciation to the Shahid Bahonar University of Kerman Faculty Research Committee Fund for its support of this investigation.

\section{REFERENCES}

[1] M. Nagarajan, X. S. Xiao, S. Antony, G. Kohlhagen, Y. Pommier and M. Cushman, "Design, Synthesis, and Biological Evaluation of Indenoisoquinoline Topoisomerase I Inhibitors Featuring Polyamine Side Chains on the Lactam Nitrogen," Journal of Medicinal Chemistry, Vol. 46, No. 26, 2003, pp. 5712-5724. doi:10.1021/jm030313f

[2] A. Fassihi, D. Abedi, L. Saghaie, R. Sabet, H. Fazeli, G. Bostaki, O. Deilami and H. Sadinpou, "Synthesis, Antimicrobial Evaluation and QSAR Study of Some 3-Hydroxypyridine-4-one and 3-Hydroxypyran-4-one Derivatives," European Journal of Medicinal Chemistry, Vol. 44, No. 5, 2009, pp. 2145-2157. doi:10.1016/j.ejmech.2008.10.022

[3] F. Manna, F. Chimenti, A. Bolasco, A. Filippelli and E. Lampa, "Antiinflammatory, Analgesic and Antipyfuztic 4,6-Disubstituted 3-Cyanopyridine-2-ones and 3-Cyano2-aminopyridines," Pharmacological Research, Vol. 26, No. 1, 1992, pp. 267-277.

doi:10.1016/1043-6618(92)91243-A
[4] A. D. Elbein and R. J. Molyneux, "The Chemistry and Biochemistry of Simple Indolisidine and Related Polyhydroxy Alkaloids," In: S. W. Pelletier, Ed., Alkaloids: Chemical and Biological Perspectives, Wiley, New York, 1981, pp. 1-54.

[5] S. S. P. Chou and P. W. Chen, "Cycloaddition Reactions of 4-Sulfur-substituted Dihydro-2-pyridones and 2-Pyridones with Conjugated Dienes," Tetrahedron, Vol. 64, No. 8, 2008, pp. 1879-1887. doi:10.1016/j.tet.2007.11.090

[6] B. B. Snider and Q. Che, "Synthesis of Cladobotryal, CJ16,169, and CJ16,170," Organic Letters, Vol. 6, No. 17, 2004, pp. 2877-2880. doi:10.1021/o1049130t

[7] M. Torres, S. Gil and M. C. Parra, "New Synthetic Methods to 2-Pyridone Rings," Current Organic Chemistry, Vol. 9, No. 17, 2005, pp. 1757-1779. doi: $10.2174 / 138527205774610886$

[8] C. Xu, J. K. Bartley, D. I. Enache, D. W. Knight and G. J. Hutchings, "High Surface Area $\mathrm{MgO}$ as a Highly Effective Heterogeneous Base Catalyst for Michael Addition and Knoevenagel Condensation Reactions," Synthesis, Vol. 19, 2005, pp. 3468-3476.

[9] I. Mohammadpoor-Baltork, M. M. Khodaei and K. Nikoofar, "Bismuth(III) Nitrate Pentahydrate: A Convenient and Selective Reagent for Conversion of Thiocarbonyls to Their Carbonyl Compounds," Tetrahedron Letters, Vol. 44, No. 3, 2003, pp. 591-594. doi:10.1016/S0040-4039(02)02516-9

[10] S. Samajdar, F. F. Becker and B. K. Banik, "SurfaceMediated Highly Efficient Regioselective Nitration of Aromatic Compounds by Bismuth Nitrate," Tetrahedron Letters, Vol. 41, No. 42, 2000, pp. 8017-8020. doi:10.1016/S0040-4039(00)01397-6

[11] B. K. Banik, N. Srivastava and S. K. Dasgupta, "A Remarkable Bismuth Nitrate-Catalyzed Protection of Carbonyl Compounds," Tetrahedron Letters, Vol. 44, No. 6, 2003, pp.1191-1193. doi:10.1016/S0040-4039(02)02821-6

[12] B. K. Banik and N. Srivastava, "Bismuth Nitrate-Catalyzed Versatile Michael Reactions," The Journal of Organic Chemistry, Vol. 68, No. 6, 2003, pp. 2109-2114. doi:10.1021/jo026550s 
[13] S. D. Samant, V. M. Alexander and R. P. Bhat, "Bismuth(III) Nitrate Pentahydrate-A Mild and Inexpensive Reagent for Synthesis of Coumarins Under Mild Conditions," Tertrahedron Letters, Vol. 46, No. 40, 2005, pp. 6957-6959. doi:10.1016/j.tetlet.2005.07.117

[14] H. Sheibani, M. Seifi and A. Bazgir, "Three-Component Synthesis of Pyrimidine and Pyrimidinone Derivatives in the Presence of High-Surface-Area $\mathrm{MgO}$, a Highly Effective Heterogeneous Base Catalyst," Synthetic Communications, Vol. 39, No. 6, 2009, pp. 1055-1064. doi:10.1080/00397910802474982

[15] M. Seifi and H. Sheibani, "High Surface Area $\mathrm{MgO}$ as a Highly Effective Heterogeneous Base Catalyst for ThreeComponent Synthesis of Tetrahydrobenzopyran and 3,4Dihydropyrano[c]chromene Derivatives in Aqueous Media," Catalysis Letters, Vol. 126, No. 3-4, 2008, pp. 275279. doi:10.1007/s10562-008-9603-5

[16] H. Sheibani and M. Babaie, "Three-Component Reaction to Form 1,4-Dihydropyrano[2,3-c]pyrazol-5-yl Cyanides,"
Synthetic Communications, Vol. 40, No. 2, 2010, pp. 257265. doi:10.1080/00397910902964866

[17] N. Y. Gorobets, B. H. Yousefi, F. Belaj and C. O. Kappe, "Rapid Microwave-Assisted Solution Phase Synthesis of Substituted 2-Pyridone Libraries," Tetrahedron, Vol. 60, No. 39, 2004, pp. 8633-8644. doi:10.1016/j.tet.2004.05.100

[18] B. K. Banik, A. T. Reddy, A. Datta and C. Mukhopadhyay, "Microwave-Induced Bismuth nitrate-Catalyzed Synthesis of Dihydropyrimidones via Biginelli Condensation under Solventless Conditions," Tetrahedron Letters, Vol. 48, No. 41, 2007, pp. 7392-7394. doi:10.1016/j.tetlet.2007.08.007

[19] M. R. H. Elmoghayar, A. A. El-Agamy, M. Y. A. Nasr and M. M. M. Sallam, "Activated Nitriles in Heterocyclic Synthesis. Part III. Synthesis of N-Amino-2-pyridone, Pyranopyrazole and Thiazolopyridine Derivatives," Journal of Heterocyclic Chemistry, Vol. 21, No. 6, 1984, pp. 1885-1887. doi:10.1002/jhet.5570210660 